\title{
HISTOPATHOLOGICAL CHANGES IN GILL, LIVER AND INTESTINE OF HETEROPNEUSTES FOSSILIS (BLOCH) TREATED WITH THREE DRY SEED EXTRACTS
}

\author{
MUNIRA NASIRUDDIN, MOHAMMAD ALI AZADI AND AKLIMA JAHAN \\ Department of Zoology, University of Chittagong, Chittagong-4331, Bangladesh
}

\begin{abstract}
Acute toxicity tests were carried out with aqueous and ethanolic extracts of three botanicals Lagerstroemia speciosa (L.) Pers, Dipterocarpus turbinatus Gaertn and Hevea brasiliensis (Willd. Ex Juss) on Heteropneustes fossilis (Bloch) under normal laboratory conditions. Extracts of $L$. speciosa were more potent than the extracts of $D$. turbinatus and $H$. brasiliensis. Histopathological changes in gill, liver and intestine of exposed fishes caused subtle cellular damages like disintegration of gill filaments and lamellae, degeneration of hepatocytes and blood vessels and necrosis of the intestinal epithelia. Different seed extracts showed histopathological variations in the different organs depending on the toxicity of the plant extracts. On the basis of histopathology, effectivity of the extract was in the order: Absolute ethyl alcohol $>50 \%$ ethyl alcohol $>$ distilled water and the effectivity of the seed extracts on the studied organs was: L. speciosa $>D$. turbinatus $>H$. brasiliensis seed extracts.
\end{abstract}

Key words: Piscicides, Histophathology, Lagerstroemia speciosa, Dipterocarpus turbinatus, Hevea brasiliensis, Heteropneustes fossilis

\section{Introduction}

Piscicides are natural biocides and used in water to increase aquaculture production. Plant piscicides are less expensive, biodegradable and enviromentally safer. The plant piscicides might help in controlling the undesirable fish species in commercial pisciculture ponds. $H$. fossilis are very hardy and are predatory in nature. It is essential to eliminate the predators from the ponds before stocking economically important fingerlings.

Different workers have studied on different fish tissues with their histological and histochemical effects by various fish poisons. Some related worth mentioning contributions to date are those of Rajan and Banerjee (1991), Dutta et al. (1993), Neskovic et al. (1996), Pandey et al.(1997), Oronsaye (1997), Poleksik and Karan (1999), Begum et al. (2001) and Akter et al. (2008). However, less information is available on the histopathological effects of plant piscicidal compounds on fish organs. Few reports on the changes in the tissues as a result of induced plant piscicidal toxins are available in Bangladesh (Latifa et al. 2002 and Nasiruddin et al. 2005, 2008) and some elsewhere (Bhatt 1991, 1992, Fafioye et al. 2004, Obomanu et al. 2007 and Olaifa et al. 2008). 
Based on the piscicidal properties of the dry seeds of Jarul (L. speciosa), Garjan ( $D$. turbinatus) and Rubber (H. brassiliensis) attempts were made to evaluate the aqueous and ethanolic extracts of these plant seeds for their potentiality as fish poisons. The objective of this study was to find the effects of the aqueous and ethanolic extracts on the histopathology of gill, liver and intestine of the predatory fish $H$. fossilis.

\section{Materials and Methods}

Dry seeds of $L$. speciosa and D. turbinatus were collected from the Chittagong University campus and $H$. brasiliensis seeds were collected from Fotikchori hill tracts of Chittagong district. Each of the plant materials was well dried in diffused sun light and preserved in air tight jars. At the prior of the experiments the seeds were pounded using metallic mortar and pestle, then crushed into fine powder with an electric grinder and sieved through $0.0025 \mathrm{~cm}^{2}$ mesh sieve. Required amount of seed powder was weighed in an electronic balance to mix with the solvents. Finely ground dry seed powder $(10 \mathrm{~g})$ was taken in a flat bottom flask and $100 \mathrm{ml}$ of distilled water or $50 \%$ ethyl alcohol or absolute ethyl alcohol was added and soaked for 3-4 hours. The flask was stirred vigorously for 34 hours with a magnetic stirrer to ensure maximum extraction of toxic components. Next the solution was filtered through fine muslin cloth. The prepared solution was kept as stock liquid extract and the different static toxicity test doses were calculated from this stock solution by appropriate dilution (APHA 1976).

To study histopathological effects of the dry seeds for $24 \mathrm{~h}$ exposure, the tissues of gill, liver and intestine were taken from the fish that were treated with the second highest concentration of the extracts and control. The tissues were processed following routine histological techniques, stained in haematoxylene and eosin and mounted with DPX. The photomicrographs of histopathological sections were taken with the help of an Axiovert 25 CFL microscope (Germany) fitted with a SLR Canon camera (Japan). Microphotographs of desired areas of the sections were taken at magnification factors using eyepiece $10 \mathrm{x}$ and objective $10 \mathrm{x}$.

\section{Results and Discussion}

The piscicidal properties of three plant seeds were studied on the test fish on the basis of histopathological effects. A number of histopathological lesions occurred in the tissues of gill, liver and intestine of this fish treated with distilled water, 50\% ethyl alcohol and absolute ethyl alcohol extracts of the seed toxicants. The observed histopathological changes were as a result of various clinical factors.

Effect of dry seed extracts on the gills of H. fossilis: Comparing with the control set, it was found that when $H$. fossilis was treated with different concentrations of seed extract, then various histopathological changes were occurred (Plate- 1A, 2A and $3 \mathrm{~A}$ ). $L$. speciosa seeds treated with different extracts such as distilled water, $50 \%$ ethyl alcohol and absolute ethyl alcohol showed that the gill, liver and intestine were very much 
affected in absolute ethyl alcohol extract. Gill filaments were normal, primary and secondary gill lamellae were swollen, gill rays and arches were vacuolated and proliferated when treated with distilled water seed extract (Plate-1B). Gill filaments were organized, primary and secondary gill lamellae were highly swollen and coalesced, gill rays and arches were distorted when treated with 50\% ethyl alcohol extract (Plate-1C). But with absolute ethyl alcohol extract, gill filaments were disorganized and damaged, primary and secondary gill lamellae were extremely swollen, clubbed, coalesced and slightly destroyed, gill rays and arches were highly swollen and proliferated with vacuolations (Plate-1D).

While treated with D. turbinatus dry seeds of distilled water, $50 \%$ ethyl alcohol and absoulate ethyl alchol extracts, changes occurred in the gills of the test fish. Gill filaments were slightly disorganized, primary and secondary gill lamellae were slightly swollen when treated with distilled water extract (Plate-1E). Gill filaments were shrunken, primary and secondary gill lamellae were swollen, gill arches were moderately torn apart when treated with $50 \%$ ethyl alcohol extract (Plate-1F). After treatment with absolute ethyl alcohol extract, gill filaments were disorganized and oedematous, primary and secondary gill lamellae were coalesced and distorted, gill rays and arches were highly swollen and damaged with vacuolation (Plate-1G).

After treatment with $H$. brasiliensis dry seeds of distilled water extract $(1 \mathrm{H})$, gill filaments were not so much organized, primary and secondary gill lamellae were less swollen, gill rays and arches were normal. With 50\% ethyl alcohol extract (Plate-1I), gill filaments were disorganized, primary and secondary gill lamellae were deshaped and oedematus, gill rays and arches were less organized. With absolute ethyl alcohol extract gill filaments were quite organized, primary and secondary gill lamellae were shrunken and coalesced, gill rays and arches were highly swollen and damaged (Plate-1J).

However, in $H$. fossilis gill lamellae were distorted and deshaped, gill filaments were disintegrated, gill rays were swollen and destroyed and gill arches were separated after being treated with Cassia siamea seed extract, whilst after treatment with Datura metel seed extract, gill filaments and gill rays swelled and gill arches were separated from the base (Nasiruddin et al. 2005). After treating with Acacia auriculaeformis seed extract, gill lamellae demolished in some places but gill filaments were organized and after treating with Mesua ferrea seed extract, the effected gill arches were disorganized and distorted, gill lamellae were shortened and swollen and gill filaments were swollen and fused in H. fossilis (Nasiruddin et al. 2008). The histopathological changes in the present observation showed similarities with the above findings. The induced histological changes in the gills may lead to several physiological stresses in the fish. It is possible that the action of the toxicants in affecting death in the fish may be due to interference with gaseous exchange in the gills by distortion of gill architecture. Necrosis, clubbing and atrophy of the gill lamellae and changes in gill architecture have implications for respiration of the fish and gill function disorder may cause death of the fish (Smart 1976). 


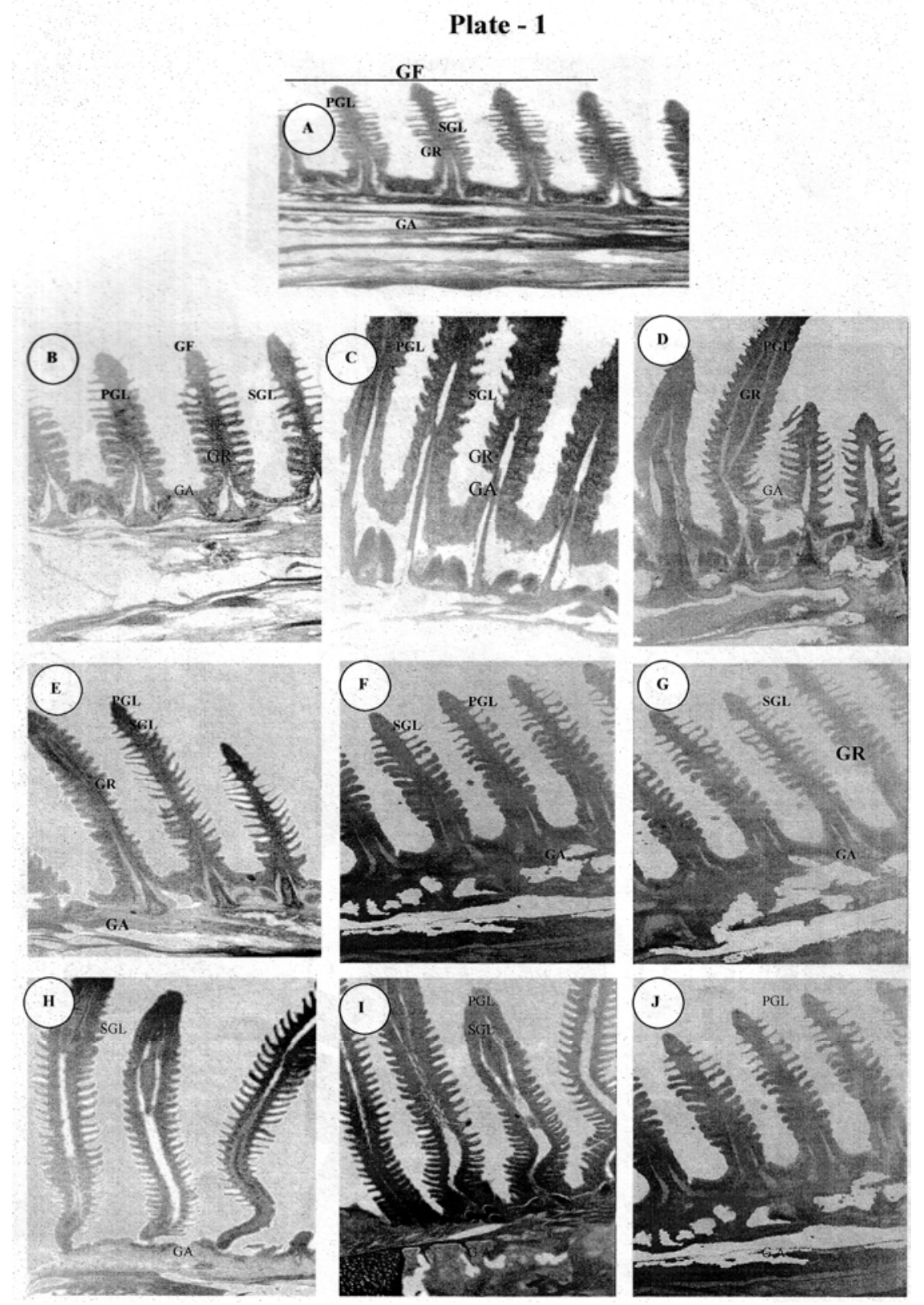

Plate-1. Photomicrographs of L.S. of control gill (1A), distilled water extract (1B), 50\% ethyl alcohol extract (1C), absolute ethyl alcohol extract (1D) of L. speciosa seed treated gills of $H$. fossilis $(\times 100)$. Photomicrographs of L.S. of distilled water extract (1E), 50\% ethyl alcohol extract $(1 \mathrm{~F})$, absolute ethyl alcohol extract $(1 \mathrm{G})$ of $D$. turbinatus seed treated gills of $H$. fossilis $(\times 100)$. Photomicrographs of L.S. of distilled water extract $(1 \mathrm{H}), 50 \%$ ethyl alcohol extract (1I), absolute ethyl alcohol extract $(1 \mathrm{~J})$ of $H$. brasiliensis seed treated gills of H. fossilis $(\times 100)$. 
Effect of dry seed extracts on the liver of $H$. fossilis: In case of liver, swollen hepatic cells, normal blood vessels and sinusoids were observed in distilled water seed extract of L. speciosa (Plate-2B). Whilst treated with $50 \%$ ethyl alcohol extract of $L$. speciosa seeds hepatic cells were swollen, pyknotic and vacuolated and sinusoids were shrunken and irregularly distributed (Plate-2C). Hepatic cells were concentrated, hepatic vein and artery were reduced and clotted with blood, when seed extract were treated with absolute ethyl alcohol (Plate-2D).

After treating the seed extract of D. turbinatus with distilled water, hepatic cells were organized and blood sinusoids were almost normal (Plate-2E). Treated with 50\% ethyl alcohol seed extract of D. turbinatus hepatic cells and blood sinusoids were normal and central vein was squeezed in size (Plate-2F). After being treated with absolute ethyl alcohol seed extract of $D$. turbinatus, hepatic cells were disintegrating and blood sinusoids underwent degeneration (Plate-2G).

While seed extract of $H$. brasiliensis were treated with distilled water, hepatic cells were well organized and blood vessels were slightly shrunken and disintegrated (Plate-2H). Parenchymatous cells were quite compact and vacuolated, blood sinusoids underwent degeneration when seed extract was treated with $50 \%$ ethyl alcohol (Plate-2I). But when seed extract of $H$. brasiliensis was treated with absolute ethyl alcohol, hepatic cells were pyknotic and vacuolated, blood sinusoids were elongated and disintegrated (Plate-2J).

Nasiruddin et al. (2005) observed that in the liver of $H$. fossilis degeneration of heptocytes occurred due to treatment with $50 \%$ ethyl alcohol extract of $C$. siamea. In the periphery, the cells were lost and the tissue became granular and nuclei pyknotic but in the central region hepatic cells were swollen and vacuolated. Whilst the fish was treated with $D$. metel seed extract localized hepatocellular degeneration with peripheral cells showing partial vacuolation was observed. Again $H$. fossilis when treated with $A$. auriculaeformis seed extracts, the hepatic cells were compactly arranged but with $M$. ferrea seed extract hepatic cells were degenerated and vacuolated, sinusoids damaged, central vein swelled and hepatic artery disintegrated (Nasiruddin et al. 2008). Hence, the effects of the experimental plant dry seed extracts showed more or less similar resemblance with the above findings. Liver necrosis was probably associated with detoxification and metabolism process of toxicants in the liver that would ultimately lead to cell death (Stoker et al. 1985). Hepatocyte vaculoation may be interpreted as evidence of lipidic degeneration and according to Hinton and Lauren (1990) lipidic degeneration is a pathological response with exposure of fish to toxins.

Effect of dry seed extracts on the intestine of $H$. fossilis: When the test fishes were treated with distilled water extract of $L$. speciosa seeds, intact serosa, slightly proliferated muscularis and slightly swollen villi were observed (Plate-3B). After treatment with 50\% ethyl alcohol extract of $L$. sepciosa, serosa, muscularis and lamnina propria were swollen and proliferated, mucosa and villi were disintegrated, shortened and fused (Plate-3C). But 
Plate -2
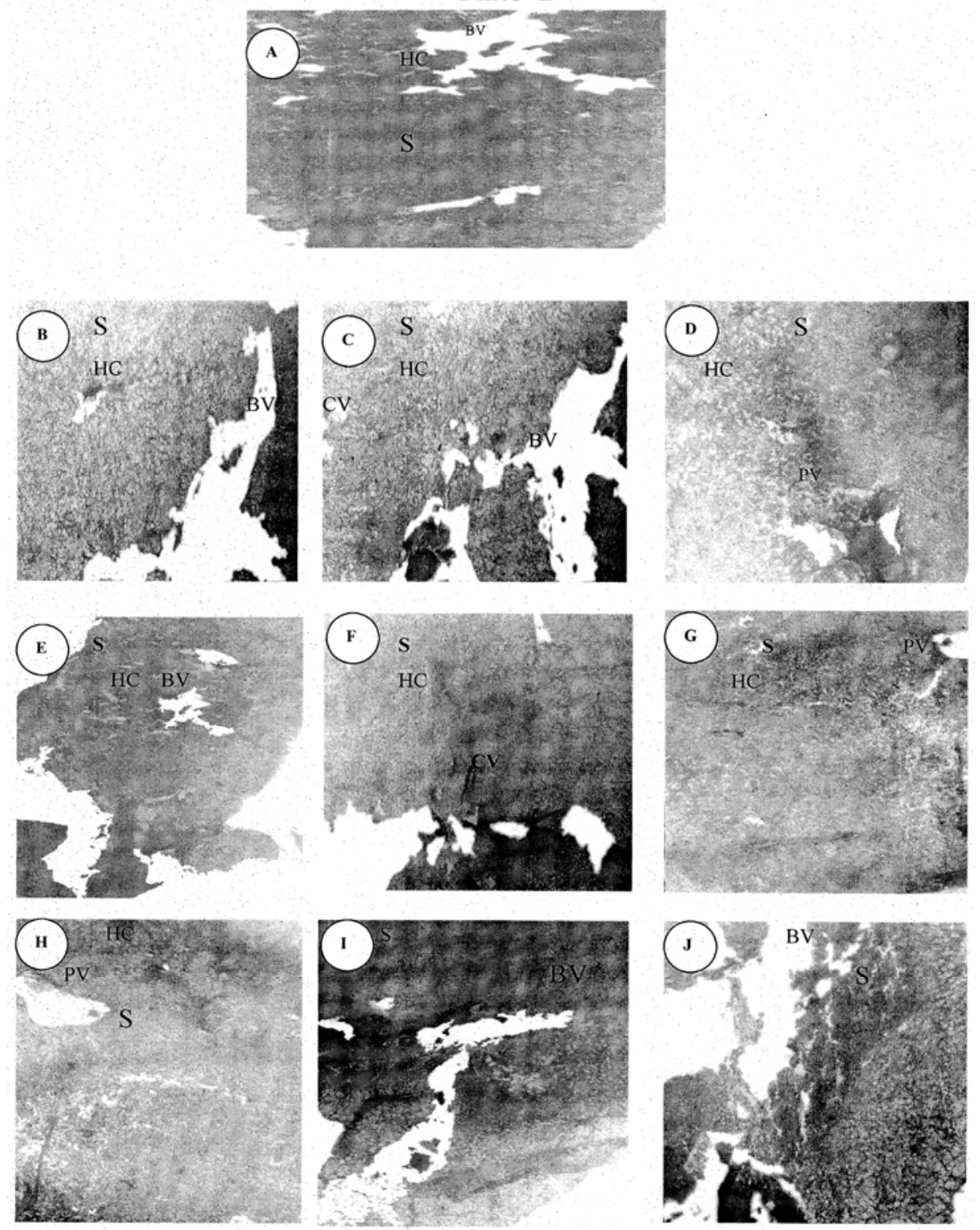

Plate-2. Photomicrographs of T.S. of control liver (2A), distilled water extract (2B), 50\% ethyl alcohol extract (2C), absolute ethyl alcohol extract (2D) of $L$. speciosa seed treated liver of $H$. fossilis $(\times 100)$. Photomicrographs of T.S. of distilled water extract $(2 \mathrm{E}), 50 \%$ ethyl alcohol extract (2F), absolute ethyl alcohol extract $(2 \mathrm{G})$ of $D$. turbinatus seed treated liver of H. fossilis $(\times 100)$. Photomicrographs of T.S. of distilled water extract $(2 \mathrm{H}), 50 \%$ ethyl alcohol extract (2I), absolute ethyl alcohol extract $(2 \mathrm{~J})$ of $H$. brasiliensis seed treated liver of $H$. fossilis $(\times 100)$. 
when treated with absolute ethyl alcohol seed extract of $L$. speciosa, damaged serosa and muscularis were separated from mucosa, submucosa and lamina propria were disintegrated, mucosa and villi were disorganized, elongated and shrunken (Plate-3D).

When the fishes were treated with of distilled water extract D. turbinatus seeds, intact serosa, slightly swollen and extended mucosa, organized lamina propria and compact villi were observed (Plate-3E). With 50\% ethyl alcohol extract of D. turbinatus seeds, serosa was intact, submucosa and lamina propria were slightly proliferated and formed network, villi were club to elongated shape (Plate-3F). After treating with absolute ethyl alcohol extract, serosa was damaged and torn apart, submucosa and lamina propria were diminished in size, mucosa and villi were swollen and shortend to elongated shape (Plate-3G).

When the fishes were treated with $H$. brasiliensis dry seed extract of distilled water, serosa was quite normal, submucosa was slightly proliferated, lamina propria was normal, mucosa and villi were slightly shrunken and elongated (Plate-3H). Being treated with $50 \%$ ethyl alcohol extract of $H$. brasiliensis seeds, serosa was disintegrating, slightly swollen and normal submucosa and lamina propria, mucosal and villi were much organized but slightly shrunken and elongated (Plate-3I). On the other hand, when fishes were treated with absolute ethyl alcohol of $H$. brasiliensis seed extract, then the serosa was damaged, lamina propria was reduced, disintegrated mucosa and irregular and extensively damaged villi were observed (Plate-3J).

Nasiruddin et al. (2005) observed that whilst $H$. fossilis was treated with $C$. siamea seed extract the serosa was damaged and muscularis mucosa was shrunken, submucosa was proliferated and consequently disintegrated and the villi were distorted and with $D$. metel seed extract muscularis mucosa and submucosa were slightly proliferated and villi were swollen and vacuolated. With $A$. auriculaeformes seed extract the serosa of $H$. fossilis was organized and muscularis mucosa was swollen, submucosa was vacuolated and disintegrated and villi were fused and whilst being treated with $M$. ferrea seed extract damaged serosa, proliferated muscularis mucosa and coalesced and fused villi were observed (Nasiruddin et al. 2008 ). Thus the present investigation on the intestine of $H$. fossilis showed somewhat close similarities with the above findings. However, necrosis of the epithelial lining of the intestine and pathological alterations of the layers might have interefered with the normal functions of the intestine. It has been reported that toxicants produced lesions on intestinal villi, necrosis of epithelial cells, degenerative epithelial and sub epithelial connective tissue and acting on the intestine mucus membrane destroyed the absorptive and secretary functions (Crane 1979).

Comparative effects of the dry seed extracts on the gill, liver and intestine of $H$. fossilis: The pathological changes in the three organs appeared to be extract-dependent. The effects of the three seed extracts in the three studied organs were found to show the following trend. 

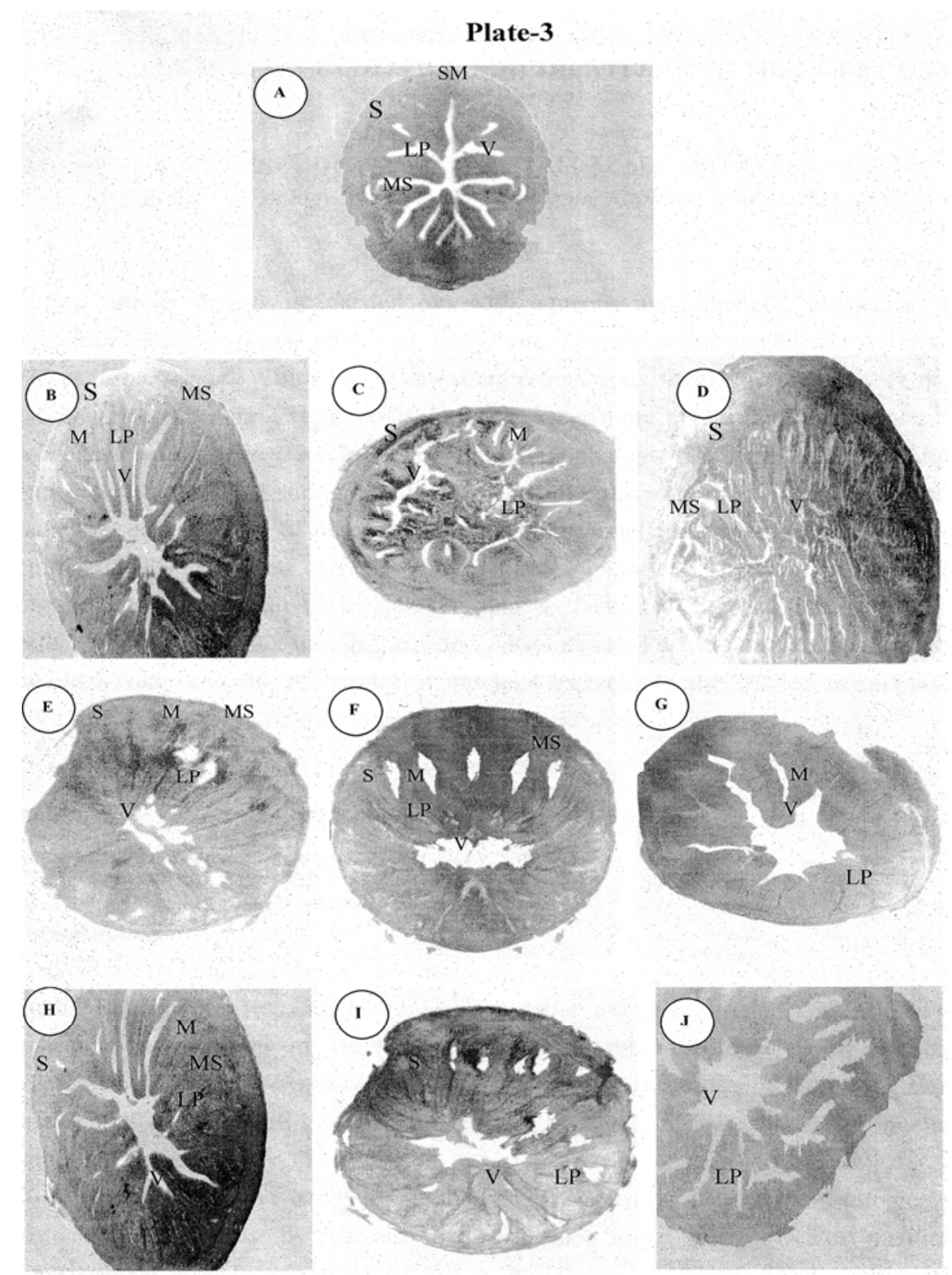

Plate-3. Photomicrographs of T.S. of control intestine (3A), distilled water extract (3B), 50\% ethyl alcohol extract (3C), absolute ethyl alcohol extract (3D) of $L$. speciosa seed treated intestine of $H$. fossilis $(\times 100)$. Photomicrographs of T.S. of distilled water extract $(3 \mathrm{E}), 50 \%$ ethyl alcohol extract (3F), absolute ethyl alcohol extract (3G) of D. turbinatus seed treated intestine of $H$. fossilis $(\times 100)$. Photomicrographs of T.S. of distilled water extract $(3 \mathrm{H}), 50 \%$ ethyl alcohol extract $(3 \mathrm{I})$, absolute ethyl alcohol extract (3J) of $H$. brasiliensis seed treated intestine of $H$. fossilis $(\times 100)$. 
Gill - Effect of L. speciosa $>$ D. turbinatus $>$ H. brasiliensis seed extracts.

Liver - Effect of L. speciosa $>H$. brasiliensis $>$ D. turbinatus seed extracts.

Intestine - Effect of L. speciosa $>$ D. turbinatus $>$ H. brasiliensis seed extracts.

Therefore, it is evident that, as to histopathology in H. fossilis, L. speciosa seed extracts caused more necrosis, $D$. turbinatus seed extracts caused moderate necrosis followed by $H$. brasiliensis seed extracts.

From the present study the result indicate, on the basis of histopathology, that the seed extracts of all the three plants are toxic to H. fossilis. L. speciosa seed extracts are more effective than seed extracts of $D$. turbinatus and $H$. brasiliensis to the test fish, while the ethanolic extracts are more potent than the aqueous extracts. So, the locally available plants might be used as piscicide that could be an alternative to harmful chemical piscicides to eradicate unwanted fishes in the ponds.

\section{References}

APHA (American Public Health Association) 1976. Standard Methods for the Examination of Water and Waste water. American Public Health Association. Inc. New York. 1193 pp.

Akter, M.S., M.K. Ahmed, M.A.A. Akhand and M.M. Islam. 2008. Acute toxicity of Arsenic and Mercury to freshwater climbing perch, Anabas testudineus (Bloch). World Journal of Zoology 3(1): 13-18.

Bhatt, J.P. 1991. Neurolytic manifestation of piscicidal flavanoid of plant, Engelhardtia colebrookiana (Lindle) in fish. Indian. J. Exp. Biol. 29: 588-590.

Bhatt, J.P. 1992. Neurodepressive action of piscicidal glycoside of plant, Aesculus indica (Colebr.) in fish. Indian. J. Exp. Biol. 30: 437-439.

Begum, S.A., F. Khanam and B. Hoque. 2001. Effects of chromium on histological structures of different organs of Clarias gariepimus (Burchel). The Chittagong Univ. J. Sci. 25(1): 110.

Crane, R.K. 1979. Intestinal structure and function related to toxicology. Environ. Health perspect. 33: 3-8.

Dutta, H.M., S. Adhikari, N.K. Singh, P.K. Roy and J.S.D. Munshi. 1993. Histopahological changes induced by Malathion in the liver of a freshwater catfish, Heteropneustes fossilis (Bloch). Bull. Environ. Contam. Toxicol. 51: 895-900.

Fafioye, O.O., A.A. Adebisi and S.O. Fagade. 2004. Toxicity of Parkia biglobosa and Raphia vinifera extracts on Clarias gariepinus Juveniles. Afr. J. Biotechnol. 3(11): 627-630.

Hinton, D.E. and D.J. Lauren. 1990. Liver structural alterations accompanying chronic toxicity in fishes: Potential biomarkers of exposure. In: Biomarkers of Environmental contaminations. Ed. McCarthy, J.F. and L.F. Shugart, Lewis Publishes, Florida. Pp 1757.

Latifa, G.A., A. Hamid and G. Sharma. 2002. Study of piscicidal activity of dry bark of Diospyros ebenum (koen) on Heteropneustes fossilis (Bloch) and Anabas testudineus (Bloch). Bang J. Life. Sci. 14(1\&2): 107-118.

Neskovic, N.K., V. Poleksic, I. Elezovi, V. Karan and M. Budimir. 1996. Periotpthalmus biochemical and histopathological effects of glyphosate in carp, Cyprinus carpio. Environ. Contam. Toxicol. 56: 295-302. 
Nasiruddin, M., M. A. Azadi and F. Tabssum. 2005. Histopathological effects of Cassia siamea (Linn.) and Datura metel (Linn.) seed extracts on Heteropneustes fossilis (Bloch) and Channa punctatus (Bloch). Bangladesh J. Zool. 33(1): 17-26.

Nasiruddin M., M.A. Azadi and I.A.S. Rahman. 2008. Histopathological changes in the gill, liver and intestine of Heteropneustes fossilis (Bloch) treated with Acacia auriculaeformis (A. Cunn. Ex. Benth) and Mesua ferrea (Linn) plant parts. Bangladesh J. Zool. 36(2): 155166.

Obomanu, F.G., O.K. Ogbalu, U.U. Gabriel, S.G.K. Fekarurhobo, S.U. Abadi. 2007. Piscicidal effects of Lepidagathis alopecuroides on mudskipper, Periophthalmus papilio from the Niger delta. Research Journal of Applied Sciences. 2(4): 382-387.

Olaifa, F.E., R.A. Hamzat and O.O. Oyetoyan, 2008. Acute toxicity of ethanol extracts of cocoa bean shell on Sarotherodon galilaeus juveniles. Journal of Fisheries International. 3(3): 56-60.

Oronsaye, J.A.O. 1997. Ultrastructural changes in the gills of the stickleback, Gasterostens aculeatus (L) exposed to dissolved cadmium in hard and soft water. J. Aquatic Sci. 12: 59-66.

Pandey, A.K., K.C. George and M. P. Mohamed. 1997. Histopathological alterations in the gill and kidney of an estuarine mullet, Liza parsia (Hamilton-Buchanan) caused by sublethal exposure to lead (pb). Indian J. Fish. 44(2): 171-180.

Poleksic, V. and V. Karan. 1999. Effects of trifluralin on Carp: biochemical and histological evaluation. Ecotoxicol. Environ. Saf. 43: 213-221.

Rajan, M. T. and T. K. Banerjee, 1991. Histopathological changes induced by acute toxicity of mercuric chloride on the epidermis of freshwater catfish, Heteropneustes fossilis (Bloch). Ecotoxicol. Environ. Saf. 22(2): 139-152.

Smart, E. 1976. The effects of ammonia exposed on the gill structure of the rainbow trout (Salmo gairdneri). J. Fish Res. Board Canza. 328-329.

Stoker T.W., J.R. Larsen, G.M. Booth and M.L. Lee. 1985 Pathology of gill and liver tissues from two genera of fishes exposed to two coal derived materials. J. Fish Biol. 27: 31-46.

(Received revised manuscript on 13.6.12) 